\title{
Game Modification of Kuru-Kuru Model For Improving Dental Hygiene Treatment of Pregnant Women
}

\author{
Francisca F Desena ${ }^{*}$, Bedjo Santoso ${ }^{2}$, Diyah Fatmasari ${ }^{3}$, Lanny Sunarjo ${ }^{4}$, \\ Waljuni Astu Rahman 5 \\ 1, 2, 3, ${ }^{4}$ Poltekkes Kemenkes Semarang, Dental Therapist and Hygienist, \\ Tirto Agung Rd., Semarang, Central Java, 50628, Indonesia \\ ${ }^{5}$ Poltekkes Kemenkes Banjarmasin, Dental Therapist and Hygienist, \\ H. MistarCokrokusumo Rd., Banjar baru,South Kalimantan 70714, Indonesia
}

\begin{abstract}
Dental and oral health problems in pregnant women are caused by poor care behavior of dental and oral hygiene as well as the condition of dental and oral hygiene of pregnant women itself. Those can lead to an impact of premature birth and low weight of the baby at birth. Strategies for behavioral change in pregnant women were one achieved through dental and oral hygiene education in the form of counseling along with material delivered that was well received by the pregnant women as the subject of research. The modification of Kuru-Kuru as game model can improve skills, self-reliance and as a media of counseling to pregnant women. The aim of research is to create KuruKuru, a game model, as an effort to improve dental health treatment to pregnant women. Research and Development method (R \& D) was adopted with model testing of quasy-experimental one-group pre-test posttest design for this research. OHI-S and the skills of pregnant women are the dependent variables. The expert validation used intra-class correlation coefficient, while for the normality test, it used Shapiro Wilk. In addition, variable of abnormal pregnant women used non-parametric test (Wilcoxon). The result of KuruKuru game model is either relevant or feasible as an effort to improve dental and oral hygiene of pregnant women shown by p-value less than 0.003 . This game effectively improves the skills of dental and oral hygiene with pre-test result in $5.92 \pm 1.158$ and post-test in $9.54 \pm 0.613(\mathrm{p}<0,000)$ and lowers the score of OHI-S pregnant women with pre-test in $1.211 \pm 0.605$ and posttest in $0.155 \pm 0.275(p<0,000)$. It can be concluded that Kuru-kuru game model is effective as an effort to shape the behavior of pregnant women in improving dental and oral hygiene.
\end{abstract}

Keywords:- Dental Hygiene, Kuru-Kuru, Pregnant Women

\section{INTRODUCTION}

Various dental and oral health problems are often encountered in the different dental and oral hygiene, gingivitis, periodontal disease and dental caries. The major problem faced by people in Indonesia and other developing countries in the field of dental and oral hygiene is dental caries and gingivitis that occurs in all circles including pregnant women[1][2].

The number of dental and oral health problems of pregnant women in Indonesia, especially dental and oral hygiene is $37.9 \%$, and gingivitis in as much as $56.7 \%$ [3][4].

Dental and oral health problems are caused by many consumption of sweet and sticky foods, lack of morning tooth brushing after breakfast and night before bedtime, chewing with both sides of the jaw and less dietary fiber intake[5] as well as the poor care behavior upon dental and oral hygiene [6]. This is proven by research demonstrating knowledge percentage in $47.2 \%$, attitudes in $44.5 \%$, and actions in $44.5 \%$ are all in bad category, meaning that there is influence of dental and oral health care behavior to OHI$\mathrm{S}$. Thus, the behavior happens through stimulus towards a person[7].

Behavioral change strategies are strengths, regulations or penalties and education. One of the strategies of behavioral change in pregnant women is through dental health education in the form of counseling with the purpose of material delivery which is expected to be well-received by them. In Timor-Leste, it takes need to pay attention to local wisdom culture. During this counseling, we only used lecture method, demonstration and props that have an influence to improve the knowledge and skills of participants[8]. However, the government need to develop other methods and media in terms of dental and oral hygiene promotion such as game of local culture (Kuru-kuru) and dice-like game. 
ISSN No:-2456-2165

An effort to improve the dental and oral hygiene of pregnant women can be performed by the innovation of Public Health Care cadre training program, implementing the local wisdom of the game, a Timor-Leste traditional game, which almost played in every area at people feast and grief. Kuru-Kuru is made of cube-shaped wood that resembles a dice. There are six surfaces on the six sides given dice one to six. This Kuru-Kuru game will be modified into a game model of Kuru-Kuru which contains dental and oral medical material for pregnant women to be performed by the UKGM (Community Dental and Oral Care) cadre as an extension media. The implementation of this Kuru-Kuru game models are as follows: training, simulation, practice and evaluation.

\section{METHODOLOGY}

The method in this research is Research and Development (R \& D). The test model used Quasyexperimental one-group pre-test post-test design. The aim of this research is to modify the model of Kuru-Kuru as dental and oral hygiene learning method [9]. The main stages include 5, i.e. data collection, design and build, expert validation and revision, model test and model result[10]. The research venue was done at Servisu Saude Komunitaria Comoro in RDTL (Republica Democratica de Timor-Leste).

The sampling technique was purposive sampling of 50 pregnant women who meet the criteria of inclusion. Intraclass statistical test correlation was done to understand the feasibility of the model. Shapiro Wilk was chosen for the normality test when the respondent amounted to less than 50. Wilcoxon test was picked for the in-pair group effectivity as the data is not normal.

\section{RESULTS}

\section{A. Data Collection}

Education of dental and oral hygiene for pregnant women can be performed through understandable delivery of material and information and in accordance with the conditions and education. Media and props facilitate the material to be understood along with the practice of toothbrushing through the simulation made it easy. Consequently, the media or games make pregnant mothers more active in playing and thinking.

\section{B. Design and Build}

The design and build of the model was made based on the results of data collection with the approach of following theories: design and modification of Kuru-Kuru game as an effort to improve the dental and oral hygiene care of pregnant women.

\section{Expert Validation}

Table 1 shows the expert validation results, in which the result is 0.003 reflecting the p-value is less than 0.05 , meaning that the game model of Kuru-Kuru modification is relevant or feasible as an effort to improve the dental and oral hygiene of pregnant women.

\begin{tabular}{|c|c|c|c|}
\hline \multicolumn{4}{|c|}{ Expert Validation* } \\
\hline n & \multicolumn{2}{|c|}{$\mathrm{f}(\%)$} & P-value \\
\hline Relevant & 3 & 100 & 0,003 \\
Irrelevant & 0 & 0 & \\
\hline
\end{tabular}

intraclass correlation coefficient

Table 1:- Statistical Validation Test From Game Expert

\section{Model Test}

Table 2 shows the normality test of skills data and OHI-S of pregnant women in a p-value of less than 0.05 . Thus, it can be inferred that the data are not normally distributed so the non-parametric test is performed.

\begin{tabular}{|l|c|c|}
\hline & Pregnant women $(\mathbf{n}=\mathbf{5 0})$ & \\
\hline & Pre-test treatment & 0,000 \\
\hline & Post-test treatment & 0,000 \\
\hline & OHI-S pre-test & 0,000 \\
\hline & OHI-S post-test & 0,000 \\
\hline
\end{tabular}

Shapiro-Wilk

Table 2:- Normality Test Results

Table 3 shows the normality data test in pregnant women. It shows that the effectiveness test of the data on the action of tooth brushing of pregnant women indicates that the $\mathrm{p}$-value of the pre-test and post-test is $0,000(\mathrm{p}<0.05)$ means that the game model of Kuru-Kuru is effective in improving the oral hygiene of pregnant women. Effectivity test of OHI-S indicates that the p-value of pre-test and posttest is $0,000(\mathrm{p}<0.05)$ meaning that the game model KuruKuru is effective in reducing the OHI-S score in pregnant women.

\begin{tabular}{|c|c|c|c|c|}
\hline \multicolumn{6}{|c|}{ Effectivity Test* } \\
\cline { 1 - 3 } & n & Mean & SD & p-value \\
\hline \multicolumn{7}{|c|}{ Pregnant women treatment } \\
\hline Pre-test & 50 & 5,92 & 1,158 & \multirow{2}{*}{0,000} \\
\cline { 1 - 3 } Post-test & 50 & 9,54 & 0,613 & \\
\cline { 1 - 2 } Pre-test & 50 & 1,211 & 0,605 & \multirow{2}{*}{0,000} \\
\cline { 1 - 3 } Post-test & 50 & 0,155 & 0,275 & \\
\hline
\end{tabular}

Wilcoxo

Table 3:- Normality Test Results

\section{E. Model Results}

The result of the model which is Kuru-Kuru, is the outcome of the dental and oral care counseling and media development. Kuru-Kuru game is played by learning through guessing numbers done by participants, in this case is pregnant women. The game is guided by dental and oral health cadres at the Maternal and Child Health Care. 

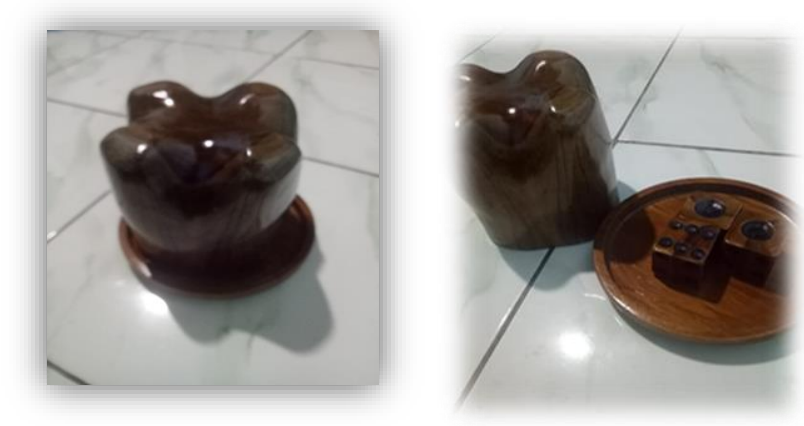

Fig 1:- Kuru-kuru Model

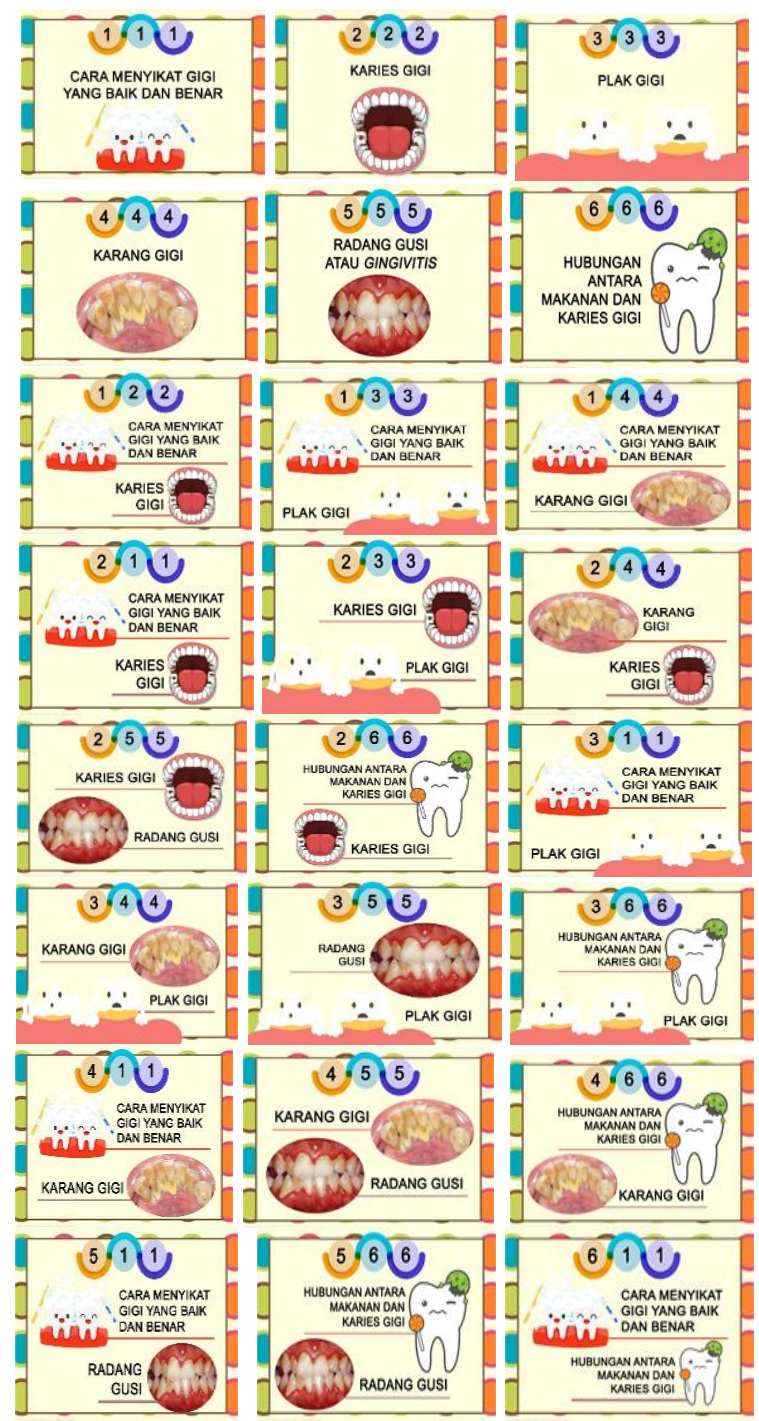

Fig 2:- Playing card with material

\section{DISCUSSION}

The results of the data collection obtained conclusions that improving skills, habit and knowledge are very important. In shaping one's actions, it is needed an effort to support learning media or counseling which is fun, useful, brings joy and stimulates the brain through playing media that involves pregnant women in their good dental and oral hygiene[11][12]. The abnormality of dental and oral hygiene of pregnant women is not explicitly because of pregnancy but due to poor dental and oral hygiene and lack of knowledge regarding dental and oral care hygiene[13].

Model design is the result of translating analysis into packages and creating a system as well as modifying or improving an existing model that is used to increase an understanding of patient for the material. The development method in this design is in the form of traditional game media, namely Kuru-Kuru[14][15].

The media is tested on several indicators of eligibility assessment from the aspect of media and material so that the media is declared fit for use. Judging from all these aspects, expert validation needs to be done to produce useful and qualified extension media [16]. The media is a tool to make it easier to deliver extension material[17].

Based on the characteristics of pregnant women that during pregnancy, the problem of nausea, vomiting, dizziness, laziness can cause the mother to pay less attention to her dental and oral hygiene so that it can have a negative impact on pregnant women and fetal growth[18][19]. Based on this problem, providing counseling to pregnant women about dental and oral hygiene through Maternal and Child Health Care handled by the cadres is a must.

An increase in the practice of dental and oral hygiene is because the cadres have been provided it with dental and oral health materials, also dental and oral hygiene including proper tooth brushing techniques through simulation practices and demonstrations using Kuru-Kuru game. One study notes that the practice of brushing directly and repeatedly is what makes people accustomed to doing it and easily applies the lesson they have received[20].

The decrease in OHI-S come up due to the advantages of Kuru-Kuru game. Besides, it is because of providing counseling through repeated games of proper tooth brushing techniques and dental and oral disease material through demonstrations. This is proven in research that brushing techniques with the correct frequency, will effectively reduces OHI-S scores and by always taking care of dental and oral hygiene, it can avoid dental and oral disease[21].

The implementation of extension media was carried out in 3 stages consisting of: Stage 1, carried out pre-test, simulation, demonstration of brushing techniques, playing Kuru-Kuru and counseling. Stage 2 is repetition of brushing teeth with the proper technique, playing Kuru-Kuru and counseling. Stage 3 is simulation, demonstration of KuruKuru. Through the game media, participants were more enthusiastic about receiving educational material, and after all, there is an increase in self-improvement of dental and oral hygiene in pregnant women. [22] 


\section{CONCLUSION}

Dental and oral hygiene problems occur on pregnant women is a challenge to solve. The use of game model to improve dental and oral hygiene is one solution. Since dental hygiene is an integral part of health especially for pregnant women, the cadres of dental and oral hygiene should play roles. This research in dental and oral hygiene for pregnant women was done using game model named Kuru-Kuru. Modification of the Kuru-Kuru model game effectively increases the dental and oral hygiene of pregnant women and decreases the OHI-S score of theirs.

\section{REFERENCES}

[1]. Indonesian Ministry of Health Indonesia Health Profile in 2014.

[2]. Health development towards a healthy Indonesia Timor regional national health work meeting, 2015

[3]. Santoso B, Sutomo B. the Influence of the gestational age level of knowledge about brushing teeth on the degree of oral and dental hygiene in pregnant women. Obstetrics journal. 2017; Volume 6, No. 13 ISSN 2089-7669

[4]. Yuniastuti A, Handayani S, the relationship between frequency and accuracy of how to brush teeth with gingivitis of pregnant women. Obstetrics journal. 2018, volume 10 No (1) 1-102.

[5]. Sunarjo L, Hendari R, Sulistijarso N. Mangosteen Rind Towards Mechanical Trauma Recovery in the Oral Cavity (in vivo). Journal of Health Research, Vol 3, No 3 (2014) p-ISSN 2252-5068 e-ISSN 2461-1026

[6]. Applonia, Priyono B, Widyanti N. Factors Influencing the Behavior of Dental and Oral Hygiene Maintenance of Pregnant Women in the Kupang District Health Center Indonesian medical magazine publisher of the university's medical faculty Gajah Mada, 2014 Vol 21, No 1

[7]. Astuti R N. Dental And Oral Health Promotion With Interactive Lecture And Demonstration Method Accompanied With Learning Tools For Elementary School Teachers As Facilitator, of 2013, IDJ, Vol. 2 No. 2

[8]. Tanjungsari R A, Palupi N, D, Widyastomo J. Effectiveness of poster media with flanelgraph on the knowledge of pregnant women in the village of Klampok Singosari Malang, 2019 E-Prodenta Journal of Dentistry. 3 (1): 187-195

[9]. Jayanti D, R, Syahrial Z, Situmorang R. Development of a technical training model for family extension workers planning to increase the competency in carrying out the training of cadres of rural / urban community institutions. Journal of Educational Technology. Vol. 21, No. 1, April 2019 http://journal.unj.ac.id/unj/index.php/jtp.

[10]. Siskawati M, Pargito, Pujiati. Development of monopolistic learning media to increase students, interest in learning geography, 2016 Journal of Social Studies, Vol 4, No 1
[11]. Yulia S, Hamid S Y A, Mustikasari. Improvement of Nurse Understanding in Implementing Patient safety Through patient safety training. Indonesian Nursing Journal, Volume 15, No. 3, November 2012; pp. 185192.

[12]. Himmamie, Y., Adi, S., \& Ratih, S, P. Development of Educational Board Games as a Media for the Promotion of Dental and Oral Health in School Age Children. Sport Science and Health, 2019, 1 (2), 164 175

[13]. Setiawan H, Adi S, Ulfah H N. Autoplay Based Interactive Multimedia Development as a Health Promotion Media About Dental and Mouth Health in Grade V Students in SDN Experiment 02 Malang City. Preventia. 2017; 2 (2). Jurnal of public health

[14]. Zulfiandri, Hidayatuloh S, Anas M. Design and Design of Dental Polyclinic (Case Study: Indonesian Attorney General Dental Polyclinic) Proceedings of the KOMMIT, 2014 - ejournal.gunadarma.ac.id Vol. 8

[15]. Radianto. Design and Development of learning media applications "Basa Samawa" Based on Android, 2019 Journal of Tambora Vol 3 No.3.

[16]. Ernawati, Iis., Sukardiyono T. "Uji kelayakan media pembelajaran interaktif pada mata pelajaran administrasi server, 2017," Elinvo (Electronics, Informatics, and Vocational Education), Vol.2 No..2 : 204-210.

[17]. Purnama, T., Rasipin, R., \& Santoso, B. (2019). The Effect of Tedi's Behavior Change Model Training on Teachers and Parents on the Teeth Brushing Skills of Preschoolers. Quality: Journal of Health, November 2019, Vol. 13 No. 2 pp. 75-81.

[18]. Tanjungsari, A, Palupi N D, Widiastomo J. Effectiveness of Poster Media with Flanelgraph on Dental and Mouth Health Knowledge in Pregnant Women Klampok Village Singosari District Malang Regency (Doctoral dissertation, Brawijaya University). E-Prodenta Journal of Dentistry. 2019.3 (1): 187-195.

[19]. Hamzah, M., Bany U Z, Sunnati. The Relationship between the Knowledge Level of Dental and Oral Health Care and Oral Hygiene in Pregnant Women at Rsud Meuraxa Banda Aceh, November 2016, Caninus Denstistry Journal, Volume 1, Number 4 : 39 - 46.

[20]. Fatmasari D, Rasipin, santoso B, Supriyana, Utami D. J. W., "Mogigu (menggosok gigi asyik dengan lagu) to increase brushing teeth of the elementary school, 2019 " J. Appl. Heal. Manag. Technol., no. 5, pp. 16-22.

[21]. Mariza A. Relationship between Education and SocioEconomy and the Occurrence of Anemia in Pregnant Women at Bps T Yohan Way Halim Bandar Lampung 2015. Journal of holistic health Vol 10, No 1, : 5-8

[22]. Syahida, Q., Wardani, R., Zubaedah, C. Levels of dental and oral hygiene of students aged 11-12 years at SDN Cijayana 1 Garut Regency Oral hygiene levels of students aged 11-12-years-old at Cijayana 1 State Elementary School of Garut Regency, 2017, Journal of Dentistry, Padjadjaran University; 29 (1). 